\title{
¿Inútiles o peligrosas?
}

\author{
- Analía Gerbaudo / Universidad Nacional del Litoral - CONICET \\ agerbaudo@fhuc.unl.edu.ar; analia.gerbaudo@conicet.gov.ar
}

Au principe de la loi, il n'y a rien d'autre que l'arbitraire.
PIerre Bourdieu, Méditations pascaliennes

En mayo de este año el gobierno francés intentó suprimir la partida de doscientos cincuenta y seis millones de euros destinada a la investigación. La medida despertó una serie de encendidos debates en la radio France Culture, entre otros medios. Si se consultan sus archivos podrán rastrearse desde los imponentes datos tomados del Banco Mundial respecto de la evolución de inversión en el rubro en la esfera mundial entre 2002 y 2012 (cabe subrayarlo: Argentina ocupa en esos rankings una posición destacada) hasta la recuperación de un hecho inquietante: el pedido que el 8 de junio de 2015 realiza el Ministro de Educación japonés a las universidades de su país de interrumpir la enseñanza de las ciencias humanas y sociales en nombre de las «necesidades de la sociedad». Tal vez llame la atención que de sesenta universidades, rápidamente veintiséis acatan esa propuesta (quien escribe no alcanza a determinar cuánto de resignación y cuánto de convicción hay en esa ¿mansa? aceptación de ese nuevo "orden global» por los agentes involucrados: sería interesante poder determinar qué posición ocupan esas instituciones en la estructura del campo así como los efectos de arrastre de esa decisión que expone su carácter heterónomo dada la vulnerabilidad, en este caso, al poder económico vía su vocero estatal).

Empiezo por el contexto internacional para enmarcar una discusión que se reactiva en Argentina, entre otros episodios, por el que en esta ocasión nos ocupa. Hace algunos meses la Comisión Interinstitucional de Elaboración de Criterios de Evaluación para las Humanidades y las Ciencias Sociales (сіесеHCs) publica una solicitada en Change.org sobre el problema que en esta revista venimos planteando de modo ininterrumpido desde su segundo número, en diálogo con este organismo. En ese sentido, el dossier «Para quién escribimos» coordinado por Isabel Quintana no podía encontrar una coyuntura más propicia que esta para 
su publicación dado que la reflexión respecto del sentido de nuestro trabajo se activa en los campos de las ciencias humanas y sociales a partir de este nuevo movimiento impulsado por la CIECEHCS (se sabe, la respuesta a la pregunta es sólo en parte individual ya que se recorta dentro de un marco de posibles, de tensiones y de luchas atravesadas por variables autónomas pero también heterónomas cuya definición escapa a la intencionalidad de los actores).

Esa pregunta por el sentido es retomada por Silvia Schwarzböck en un capítulo de Los espantos. Estética y posdictadura. En su aguda y controversial lectura de la herencia cultural y económica del «Proceso», conjetura respecto de cómo se naturaliza la "vida intelectual burocratizada» (Schwarzböck:87), hoy expandida. Su hipótesis es que no son ni los contenidos seleccionados en las carreras de humanidades y de ciencias sociales ni la forma en que se los enseña lo que contribuye a su naturalización sino su evaluación. Lejos de rechazar este último procedimiento, lo que Schwarzböck cuestiona gira sobre el mismo eje que la mayor parte de los comentarios motivados por la solicitada de Change.org: el privilegio del criterio cuantitativo sobre el cualitativo que tiene como corolario una vertiginosa carrera contra el tiempo. Sobre este punto se despacha con alta dosis de ironía: «la cantidad de antecedentes acumulados en la menor cantidad de tiempo posible equivale, de suyo, al concepto deportivo de carrera» (87).

A este problema se agregan otros ya analizados en las editoriales previas. Baste agregar que hay resultados de investigación que, dada la lengua en la que circulan, los objetos sobre los que versan y la posición de los agentes respecto de su difusión, parecieran perfilados a permanecer, como postulan Johan Heilbron e Yves Gingras para ciertos temas de las ciencias sociales europeas, en el orden «local y nacional» (379). ¿Estaremos en condiciones de valorar esta circulación y/o de advertir su importancia estratégica más allá de su internacionalización?

Por otro lado parecieran tener razón Heilbron y Gingras cuando señalan que «sería equívoco tomar los procedimientos de las ciencias naturales como el único modelo sin tener en cuenta las especificidades propias de las ciencias sociales y humanas que hacen que sus objetos no puedan circular del mismo modo que los de las ciencias naturales» (379). La evidencia empírica disponible ${ }^{1}$ permite aseverar que, en el caso particular de los estudios literarios made in Argentina, esta cuestión es inescindible de las tomas de posición atravesadas, en muchos casos, por activismos indisociables de las fantasías de intervención de los agentes que eligen, por ejemplo, no sólo escribir únicamente en español («una de las lenguas del conocimiento», insiste Daniel Link) sino además hacerlo desde una variante del habla rioplatense o, más aún, desde una inflexión atravesada por las marcas de las lenguas de los pueblos originarios o del registro "criollo». Algunos de estos agentes no sólo publican fundamentalmente bajo el formato libro sino que además, a partir de un extraño «bucle» cuya recursividad asombraría al propio Hofstadter, traducen a este formato sus intervenciones en blogs o en Facebook, en sus diarios o en sus notas de viaje. Otros «gastan» su tiempo en traducir o en hacer extensión o divulgación: prácticas de baja medición en la escala de productividad 
científica en Argentina pero nodales para expandir las esferas de circulación social de los bienes culturales que producimos y/o de los que nos apropiamos.

Muchos de quienes ejercen esas formas de resistencia integran el comité científico de esta revista (entre ellos, y a partir de este número, Silvio Mattoni y Cristina Rodríguez Marciel, a quienes les damos la bienvenida). Me atrevo a afirmar que para todos ellos, la producción en ciencias humanas y sociales es una «necesidad»: su desestimación en nombre del utilitarismo es el síntoma de algo que, como en otras ocasiones y en otros momentos de nuestra historia, deja entrever su potencial, su carácter tal vez peligroso, su condición quizás «subversiva».

\section{Notas}

${ }^{1}$ Hago referencia aquí a los datos en proceso de aná- Programme FP7/2007-2013/ Grant Agreement N ${ }^{\circ}$ 319974) lisis en el marco de la investigación grupal International dirigida por Gisèle Sapiro. Los resultados derivados de diCooperation in the Social Sciences and Humanities: Com- cho análisis se publicarán en 2017 en un Segundo Informe parative Socio-Historical Perspectives and Future Possibili- Técnico a colgar, como el primero, en la página del misties (INTERCO SSH, European Union Seventh Framework mo Centro de Investigaciones que produce esta revista.

\section{Bibliografía}

Heilbron, Johan e Yves Gingras (2009). «Linternationalisation de la recherche en Sciences Sociales et humaines en Europe (1980-2006) ", en L'espace intellectuel en Europe. De la formation des États-nations à la mondialisation (XIXe-XXIe siècle). París: La Découverte, 39-390. LinK, DANiEL (2OI5). Consulta. CiC, PIP-CONICET/INTERCO SSH-EHESS.

Schwarzböck, Silvia (20I6). Los espantos. Estética y postdictadura. Buenos Aires: Las cuarenta y El río sin orillas. 